\title{
The Impact of Human Resource Management System on Enterprise Sustained Competitive Advantage in Competitive Strategy: The Mediating Role of Human Capital*
}

\author{
Zhang Yanli \\ Liu Shun \\ Li Weibao \\ School of Economics and management \\ North China Institute of Aerospace Engineering \\ Guangyang District, Langfang \\ China
}

\begin{abstract}
Facing the trend and characteristics of "new normal" in China's economic development, enterprises are facing increasingly fierce market competition and more complex problems in human resource management practice. This paper makes an empirical study on the mediating role of human capital in the relationship between human resource management system and sustainable competitive advantage of enterprises through a questionnaire survey of 779 enterprises in China. The results show that, firstly, the human resource management system and human capital need to be differentiated for enterprises to implement different competitive strategies, and secondly, different types of human capital have different energy efficiency in different competitive strategies, the mediating role of internal development human capital adopting in differentiation strategy is greater than external acquisition human capital when implementing cost reduction strategy. The study of this paper provides a practical situation test of the relationship among human resource management system, human capital and sustainable competitive advantage, which can be used for reference for the practice of enterprise management.
\end{abstract}

Keywords: Human Resource Management System; Human Capital; Sustainable Competitive Advantage; Competitive Strategy

\section{Introduction}

Faced with the trend and characteristics of the "new normal" of China's economic development, enterprises are facing increasingly fierce and unpredictable market competition, and it is increasingly difficult for them to maintain their sustainable competitive advantage. In the changing market environment, human capital is becoming more and more important for enterprises to obtain sustainable competitive advantage. More and more enterprises begin to pay attention to how the human capital promotes the successful implementation of the enterprise strategic goal. At the same time, based on the strategic objective, how to carry out the practice of human resource management, how to train, select and evaluate the employees in the organization, and so on, so as to form the various elements of human capital that match the competitive strategy, all of these will influence the achievement of the enterprise's strategic objective and gain the sustainable competitive advantage (Gill, 2018).

*This paper is supported by the Ministry of Education of the People's Republic of China 's Youth Foundation for Humanities and Social Sciences Research Project (Project No. 19YJC630220) and the Scientific Research Fund of North China Institute of Aerospace Engineering (Project No. BKY-2018-26). 
In the existing literature, the relevant foreign literature on human capital can be used as a strategic resource for enterprises in a more detailed discussion (Carmeli, 2004). But under different competitive strategies, what are the characteristics of human capital and the human resource management system that forms the value of human capital, and the mechanism of how they affect the sustainable competitive advantage are not explained based on empirical research (Ployhart, 2015) .

This paper holds that the human capital matching the competitive strategy refers to the cost reduction strategy and the differentiation strategy, including the knowledge, skills and abilities of the employees. Based on the different competitive strategies, human resource management system and human capital must be differentiated. Through the different mediating role of human capital, this paper makes an empirical study on the impact of differentiated human resource management system on the sustainable competitive advantage of enterprises. It provides a real situation test of human resource management system, human capital and sustainable competitive advantage for Chinese enterprises. It also provides theoretical guidance for enterprise managers to manage, develop and maintain human capital with strategic value, and provides microcosmic guidance for improving and perfecting China's human resource management practice.

\section{Literature review}

Under the different competition strategies, the enterprise's human resources practice is also different, the domestic and foreign scholars had done a great deal of theoretical and practical research on the different forms of human resource management and the impact on the sustained competitive advantage of enterprises (Greer et al. , 2017). James et al. (2009) based on resource-based theory and taking Irish firms as a sample, showed that high-performance work systems had positive impact on firm performance. Li Xuefeng and Jiang Chunyan (2011) conducted an empirical study on the relationship between strategic human resource management and corporate performance in a sample of 154 enterprises in Tongzhou district in Nantong. Pereira and Gomes (2012) studied the relationship between human resource management systems, leadership, organizational environment and firm performance by using a sample of 323 corporate questionnaires, the mediating role of organizational environment in human resource management system and enterprise performance was not significant, but it could be used as the mediating variable between leadership and enterprise performance. Yang Hao and Liu Jiawei (2015) argued that employee behavior could act as a mediator between human resource management and firm performance. Bal and Dorenbosch (2015) examined the impact of diverse human resource management on organizational performance and the role of age differences in the relationship between the two variates. Tang Guiyao et al. (2016) analyzed the impact of strategic human resource management on new product development performance by using the paired data of 151 group CEO in Chinese manufacturing enterprises. Zhao Shuming and Sun Xiuli (2016) conducted an empirical analysis of 168 small and medium-sized enterprises in the beijing-tianjin-hebei region, the results showed that strategic human resource management could act as a partial mediator between CEO's transformational leadership behavior and firm performance. Tian Lifa (2017) based on the survey data of 164 high-tech enterprises in beijing-tianjin-hebei region, this paper used structural equation model to test the relationship between human resource management practices, organizational climate strength and enterprise performance, the results showed that incentive practice had a significant direct effect on enterprise performance, and it was the best human resource management practice. Li Genqiang et al. (2019) considered that exhibition-type human resource management practices have a direct and positive impact on job performance.

In foreign literatures, Poter(1980) and Schuler and Jackson (1987) and Delery and Doty (1996) divided the competitive strategy and human resources management system(HRMS). This paper referes to the above literature, according to the cost reduction strategy and the differentiation strategy, the human resource management system is divided into internal development human resources management system (IHRMS) and external acquisition human resources management system (EHRMS). The IHRMS focuses on the internal generation of human capital with high levels of knowledge, skills and competencies that match the differentiation strategy. In order to reduce costs, 
EHRMS focuses on acquiring the knowledge, skills and competencies of employees directly from the external market, matching the cost reduction strategy. In this paper, the paper concludes that human resource management systems have positive effects on sustained competitive advantage (SCA) under different competitive strategies, the following hypothesis is proposed:

H1: On differentiation strategy, IHRMS have positive impact on SCA.

H2: On cost reduction strategy, EHRMS have positive impact on SCA.

At present, from the literature, some scholars had explored the relationship between human resource management system and enterprise human capital. Zhu Weimin (2009) took 83 new high-tech enterprises as an example, proved that the practice of strategic human resource management could be used to improve the knowledge creation ability of the organization and the human capital level of the employees. Jiang Jianwu and Zhao Shuming (2011) argued that diverse human resource management practices affected employees' creativity, and human resource management interact with one another. Huang et al. (2016) considered that high-performance work system could stimulate the employee's job well-being and enhance the employee's ability to participate through empirical research. Lin Xinqi and Ding he (2017) believed that the intensity of human resource management had a positive impact on employees'innovation ability and intention. Kianto et al. (2017) took 180 Spanish companies as an example, through the survey data proved that the human resource management practices of enterprises could enhance the knowledge acquisition ability of employees, and then could affect the overall intellectual capital of enterprises, generated higher innovation performance. Haneda and Ito (2018) studied the relationship between human resource management and employees' innovation ability by using the survey of Japanese enterprises.

Different competitive strategies focus on different human resource management practices, and different knowledge, skills and abilities of employees are generated. Under the differentiation strategy, through IHRMS to enhance the human capital value of employees, to form internal development human capital (IHC). Under the cost reduction strategy, EHRMS form external acquisition human capital (EHC). Based on the literature review, this paper argues that human resource management systems have positive effects on the value generation of human capital under different competitive strategies, the following hypothesis is proposed:

H3: On differentiation strategy, IHRMS have positive impact on IHC.

H4: On cost reduction strategy, EHRMS have positive impact on EHC.

In the study of human resource management system and enterprise sustainable competitive advantage, some scholars studied the mediating variable between them, that is the "black box" problem. Human capital is one of the most mediating variables(Abdul et al., 2017; Ni Jiacheng et al., 2018). Youndt et al. (2004) argued that human capital played a mediating role in the relationship between human resource management and firm performance, but it played a partial mediating role rather than a full mediating role, and the relationship was influenced by other factors. Chin-yen and Tsung-Hsien (2007) argued that human resource management had an impact on employees' knowledge management and organizational learning, which in turn influences firm performance. Takeuchi et al. (2009)argued that high-performance systems generated relatively high levels human capital of organizational level. Medina et al (2011) believed that not only human capital, social capital was also the mediating variable beteen human resource management and enterprise innovation performance. Alfes et al. (2013) conducted a survey of 297 service sector employees in the UK and founded that human resource management practices influenced organizational citizenship behavior and turnover intention, and employee engagement could play a mediating role. Sun Yue (2014) believed that the practice of strategic human resource management could promote the innovation ability of $R \& D$ personnel through the function of organizational innovation atmosphere, and then affected enterprise performance. Wang et al. (2015) belived that human resource management could influence the organizational performance through the mediating effect of human capital. Wang Xia and Wu Jiabao(2016) considered that organizational learning could be used as an mediating variable between human resource management and organizational performance, and put forward a model to test the hypothesis. Li Jianxin et al (2017) described the strategic attributes of human capital, analyzed the construction of organizational human capital pool. 
Li Xinchun et al. (2019) studied the contribution rate of human capital and social capital to enterprise performance, enterprises should pay attention to the management of human capital.

In summary, this paper holds that human capital matching competitive strategy is based on the collection of employees' experience, knowledge and skills, and promotes the value of human capital through human resource management system, and then affect the sustainable competitive advantage of enterprises. Thus, the following hypothesis is proposed:

H 5: IHC mediates the relationship between IHRMS and SCA.

H6: EHC mediates the relationship between EHRMS and SCA.

H7: The mediating role of IHC and EHC is different.

The theoretical framework of this paper is shown in Fig. 1.

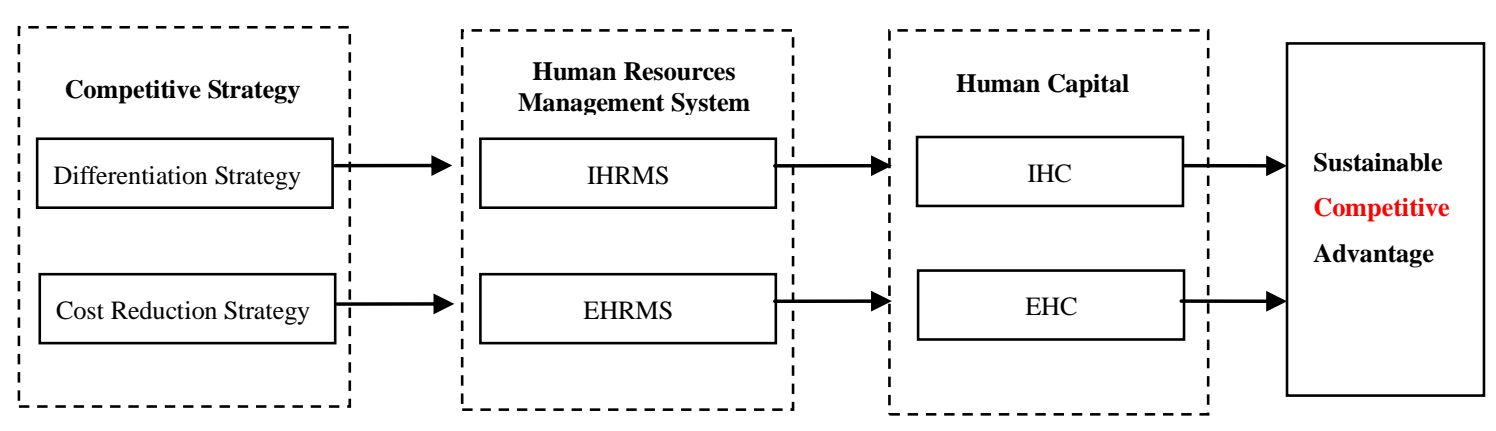

Fig. 1 Theoretical framework of this paper

\section{Research process and methodology}

\section{1study sample}

In order to test the proposed hypothesis and to ensure that the respondents are aware of the relevant information in the enterprise questionnaire, a questionnaire survey is conducted among the general managers, department functional managers and human resource management staff of enterprises in Beijing, Hebei, Tianjin and other provinces. A total of 1600 questionnaires are distributed, and 779 invalid questionnaires are collected. The effective recovery rate is $48.69 \%$. In the valid questionnaire, it includes 11 industries, such as manufacturing, wholesale and retail, information transmission, computer services and software.

\section{2 the measurement of variables}

The measurement scale of human resource management system mainly refers to the design of Delery and Doty(1996), MacDuffie(1995), Youndt et al.(1996), including selection, career planning, salary management, internal promotion, team information sharing and other dimensions. The measurement scale of human capital mainly refers to the design of Yeh and Chen (2007), and is revised from the perspective of competitive strategy through interviews, it includes three aspects: knowledge, technology and capability form. The measurement scale of sustainable competitive advantage mainly refers to the design of Helfat et al (2003), Dyer 和 Reeves ( 1995 ), including human resource performance, technology matching, competitive position and customer value.

\section{Research results}

\section{1 reliability analysis}

Reliability analysis is mainly used to test the reliability of the data measured by the scale. Cronbach's a coefficient is used to measure the reliability of each scale. When Cronbach's a is greater than 0.7 ,it is considered acceptable range. As shown in Table 1, the Cronbach's a of each scale are above 0.7, which shows that all three subscales have good measurement reliability. 
Table 1: Reliability analysis of the scale

\begin{tabular}{lccc}
\hline \multicolumn{1}{c}{ Variable } & Dimensions & $\begin{array}{l}\text { Cronbach's a } \\
\text { of each dimension }\end{array}$ & $\begin{array}{l}\text { Cronbach's a } \\
\text { of the scale }\end{array}$ \\
\cline { 1 - 3 } $\begin{array}{l}\text { Human Resources } \\
\text { Management System }\end{array}$ & IHRMS & 0.74 & \multirow{2}{*}{0.87} \\
\cline { 2 - 3 } & EHRMS & 0.84 & \multirow{2}{*}{0.79} \\
\cline { 2 - 3 } Human Capital & IHC & 0.78 & \multirow{2}{*}{0.83} \\
\hline $\begin{array}{l}\text { Sustainable Competitive } \\
\text { Advantage }\end{array}$ & - & - & 0.79 \\
\hline
\end{tabular}

\section{2 validity analysis}

The scale of this paper refers to the mature scale of the literature, and modifies the items of the scale through the interview, therefore, the scale has high content validity. Exploratory factor analysis is used to test the discriminant validity of each subscale. The premise of exploratory factor analysis test is that both KMO and Bartlett values meet the requirements. If $\mathrm{KMO}$ value is less than 0.6, exploratory factor analysis is not suitable. As shown in Table 2, the $\mathrm{KMO}$ of each variables are greater than 0.6, and the Sig. statistic of Bartlett test was less than 0.001. Exploratory factor analysis could be performed. In the design of the scale, only the human resource management system and the human capital scale are tested in the exploratory factor analysis, because the sustainable competitive advantage of the enterprise is taken as a factor. As shown in Table 3, the load of each factor is greater than 0.5 . The result shows that the validity of human resource management system and human capital are good.

Table 2: KMO and Bartlett test results of the scale

\begin{tabular}{cccc}
\hline Variable & KMO & df & Sig. \\
\hline Human Resources Management System & 0.88 & 66 & 0.000 \\
Human Capital & 0.74 & 105 & 0.000 \\
Sustainable Competitive Advantage & 0.83 & 36 & 0.000 \\
\hline
\end{tabular}


Table 3: Results of exploratory factor analysis

\begin{tabular}{|c|c|c|c|c|}
\hline Variable & Dimensions & Projects & Factor 1 & Factor 2 \\
\hline \multirow{15}{*}{$\begin{array}{l}\text { Human Resources } \\
\text { Management System }\end{array}$} & \multirow{8}{*}{ IHRMS } & ihs1 & 0.69 & 0.29 \\
\hline & & ihs2 & 0.67 & 0.49 \\
\hline & & ihs3 & 0.78 & 0.37 \\
\hline & & ihs4 & 0.59 & 0.26 \\
\hline & & ihs5 & 0.56 & 0.27 \\
\hline & & ihs6 & 0.57 & 0.15 \\
\hline & & ihs7 & 0.70 & 0.42 \\
\hline & & ihs8 & 0.57 & 0.47 \\
\hline & \multirow{7}{*}{ EHRMS } & ehs1 & 0.19 & 0.65 \\
\hline & & ehs2 & 0.02 & 0.65 \\
\hline & & ehs3 & 0.24 & 0.56 \\
\hline & & ehs4 & 0.36 & 0.51 \\
\hline & & ehs5 & 0.06 & 0.57 \\
\hline & & ehs6 & 0.45 & 0.68 \\
\hline & & ehs7 & 0.25 & 0.75 \\
\hline \multirow{12}{*}{ Human Capital } & \multirow{7}{*}{$\mathrm{IHC}$} & ihc1 & 0.72 & 0.25 \\
\hline & & ihc2 & 0.56 & 0.32 \\
\hline & & ihc3 & 0.59 & 0.25 \\
\hline & & ihc4 & 0.70 & 0.13 \\
\hline & & ihc5 & 0.71 & 0.11 \\
\hline & & ihc6 & 0.76 & 0.12 \\
\hline & & ihc7 & 0.53 & 0.43 \\
\hline & \multirow{5}{*}{ EHC } & ehc1 & 0.32 & 0.65 \\
\hline & & ehc2 & 0.32 & 0.56 \\
\hline & & ehc3 & 0.48 & 0.59 \\
\hline & & ehc4 & 0.49 & 0.54 \\
\hline & & ehc5 & 0.05 & 0.69 \\
\hline
\end{tabular}

Note: ihs 1 represents the first entry of the internal human resource management system scale, and the rest are the same.

\section{3 descriptive statistical analysis}

The results of Table 4 show that there is a significant correlation among the variables, and the correlation is positive.

Table 4:Average, standard deviation and pearson correlation coefficients for each variable

\begin{tabular}{|c|c|c|c|c|c|c|c|}
\hline Variable & Average & $\begin{array}{l}\text { Standard } \\
\text { Deviation }\end{array}$ & IHRMS & EHRMS & IHC & EHC & SCA \\
\hline IHRMS & 3.500 & 0.566 & 1 & & & & \\
\hline EHRMS & 3.435 & 0.544 & $0.719 * *$ & 1 & & & \\
\hline $\mathrm{IHC}$ & 3.650 & 0.587 & $0.554^{* *}$ & $0.508^{* *}$ & 1 & . & \\
\hline EHC & 3.845 & 0.545 & $0.575^{* *}$ & $0.521^{* *}$ & $0.687^{* *}$ & 1 & \\
\hline SCA & 3.438 & 0.601 & $0.452 * *$ & $0.498 * *$ & $0.555^{* *}$ & $0.431^{* *}$ & 1 \\
\hline
\end{tabular}

Note: $\mathrm{N}=779, * * \mathrm{P}<0.01$. 


\section{4 empirical test}

\subsubsection{An examination of the mediating role of IHC between IHRMS and SCA}

The model to test the mediating variable goes through three steps. First, examining the relationship between IHRMS and SCA. Second, examining the relationship between IHRMS and IHC. Finally, examining the mediating role of IHC between IHRMS and SCA. As shown in Fig. 2, Building structural equation model.The result of the model shows that the path coefficient between IHRMS and SCA is $0.67 （ \mathrm{P}<0.001)$. The evaluation index is good, the positive influence of IHRMS on SCA is significant, and the hypothesis of $\mathrm{H} 1$ is valid.

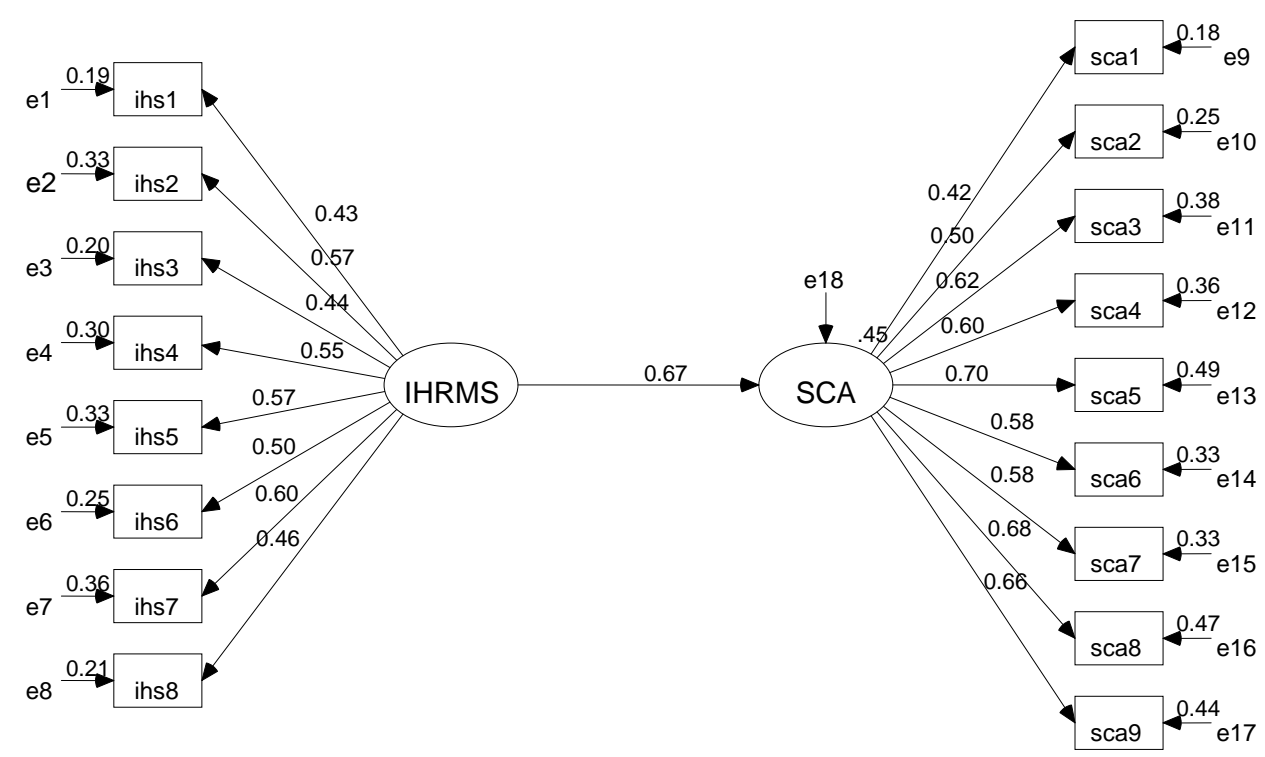

Fig. 2 The model analysis result of IHRMS and SCA

As shown in Fig. 3, The result of the model shows that the path coefficient between IHRMS and IHC is 0.70 $(\mathrm{P}<0.001)$. The evaluation index is good, the positive influence of IHRMS on IHC is significant, and the hypothesis of $\mathrm{H} 3$ is valid.

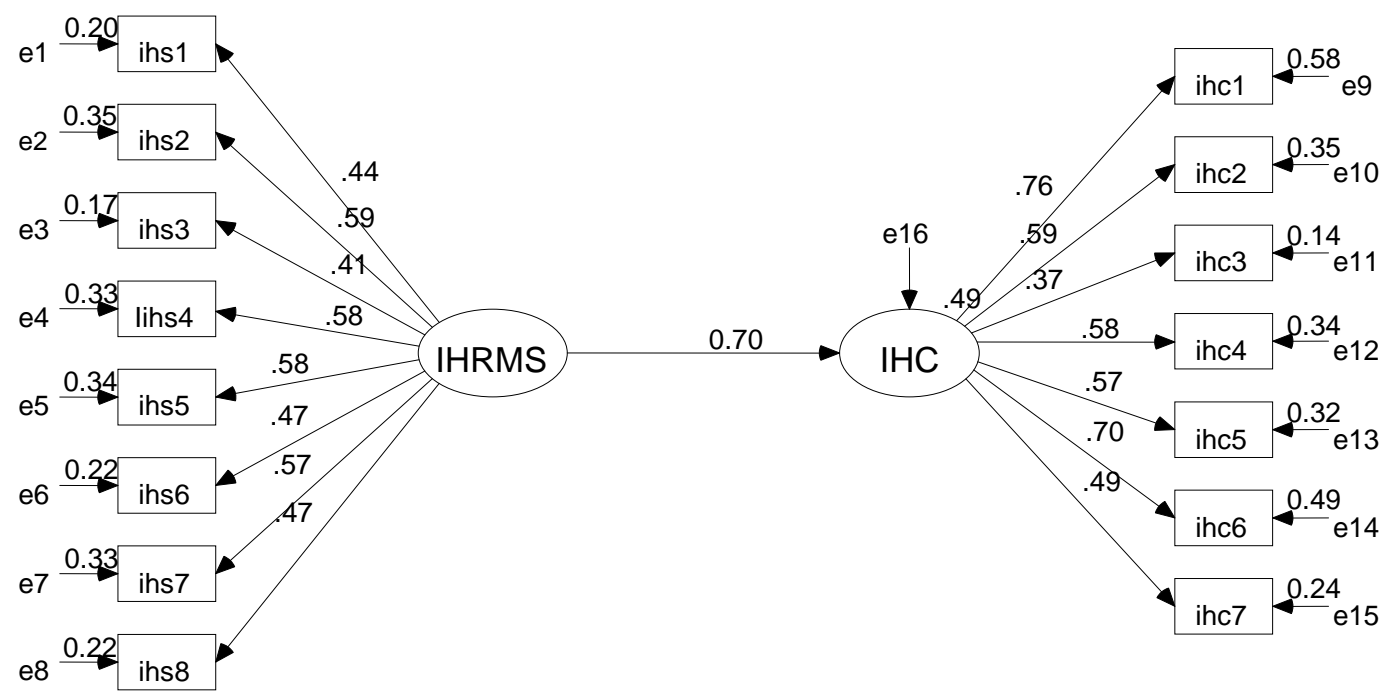

Fig. 3 The model analysis result of IHRMS and IHC

As shown in Fig. 4, the structural equation model is constructed with IHC as an mediating variable. The results show that the path coefficient of IHRMS to IHC is $0.70(\mathrm{P}<0.001)$, IHC to SCA is $0.41(\mathrm{P}<0.001)$, and IHRMS to SCA is $0.38(\mathrm{P}<0.001)$. And the path coefficient of IHRMS to SCA is 0.38 less than that 0.67 of $\mathrm{H} 1$. It is shown that IHC plays a partial mediating role in IHRMS and SCA. The calculation formula of the mediating effect of IHC is $0.70 \times 0.41 / 0.67=0.4284$, the proportion of the mediating effect of IHC is close to $42.84 \%$. 
The evaluation index is good and the hypothesis of H5 is valid.

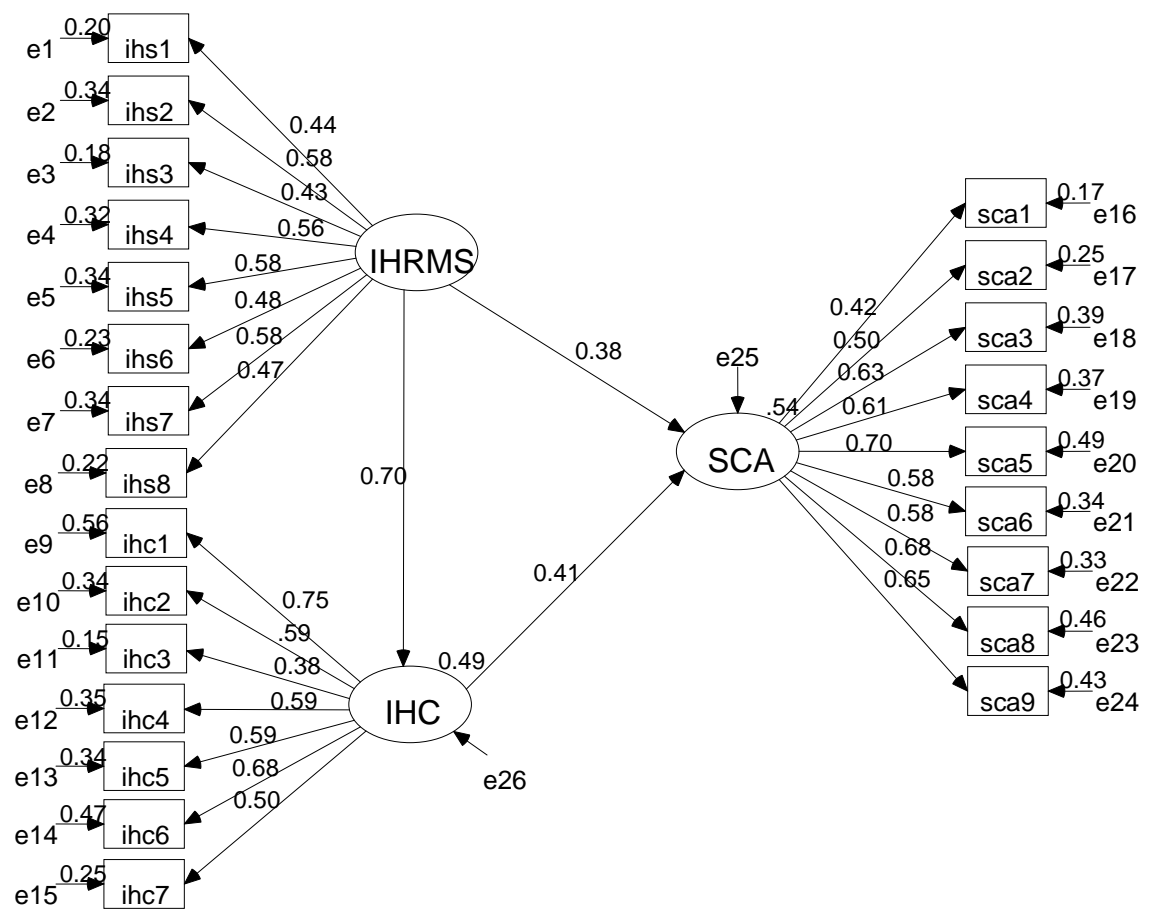

Fig. 4 The model analysis result of IHC's mediating role

\subsubsection{An examination of the mediating role of EHC between EHRMS and SCA}

As shown in Fig. 5, The result of the model shows that the path coefficient between EHRMS and IHC is 0.69 $(\mathrm{P}<0.001)$. The evaluation index is good, the positive influence of EHRMS on SCA is significant, and the hypothesis of $\mathrm{H} 2$ is valid.

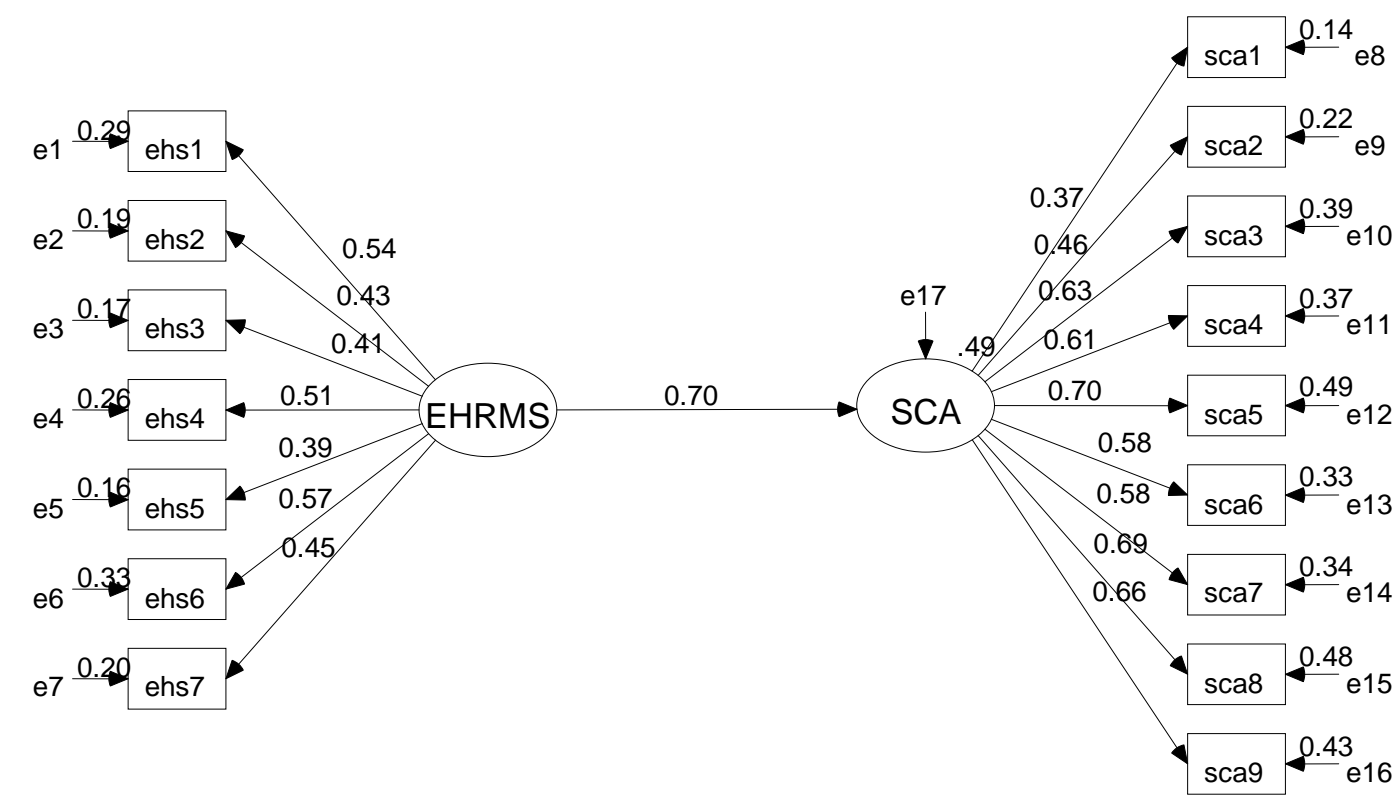

Fig. 5 The model analysis result of EHRMS and SCA

As shown in Fig. 6, The result of the model shows that the path coefficient between EHRMS and EHC is 0.77 $(\mathrm{P}<0.001)$. The evaluation index is good, the positive influence of EHRMS on EHC is significant, and the hypothesis of $\mathrm{H} 4$ is valid. 


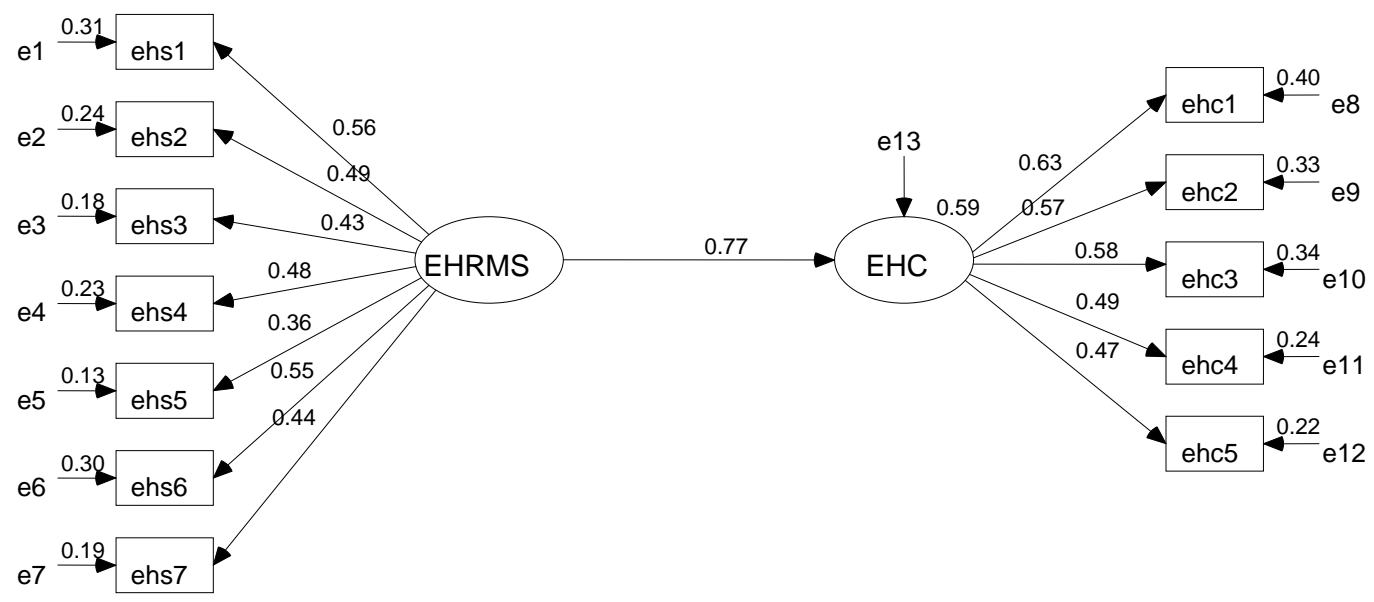

Fig. 6 The model analysis result of EHRMS and EHC

As shown in Fig. 7, the structural equation model is constructed with EHC as an intermediary variable. The results show that the path coefficient of EHRMS to EHC is $0.77(\mathrm{P}<0.001)$, EHC to SCA is $0.22(\mathrm{P}<0.001)$, and EHRMS to SCA is $0.53(\mathrm{P}<0.001)$. And the path coefficient of EHRMS to SCA is 0.53 less than that 0.69 of $\mathrm{H} 2$. It is shown that EHC plays a partial mediating role in IHRMS and SCA. The calculation formula of the mediating effect of $\mathrm{EHC}$ is $0.77 \times 0.22 / 0.70=0.242$, the proportion of the mediating effect of $\mathrm{EHC}$ is close to $24.2 \%$. The evaluation index is good. And the hypothesis of $\mathrm{H} 6$ and $\mathrm{H} 7$ are valid.

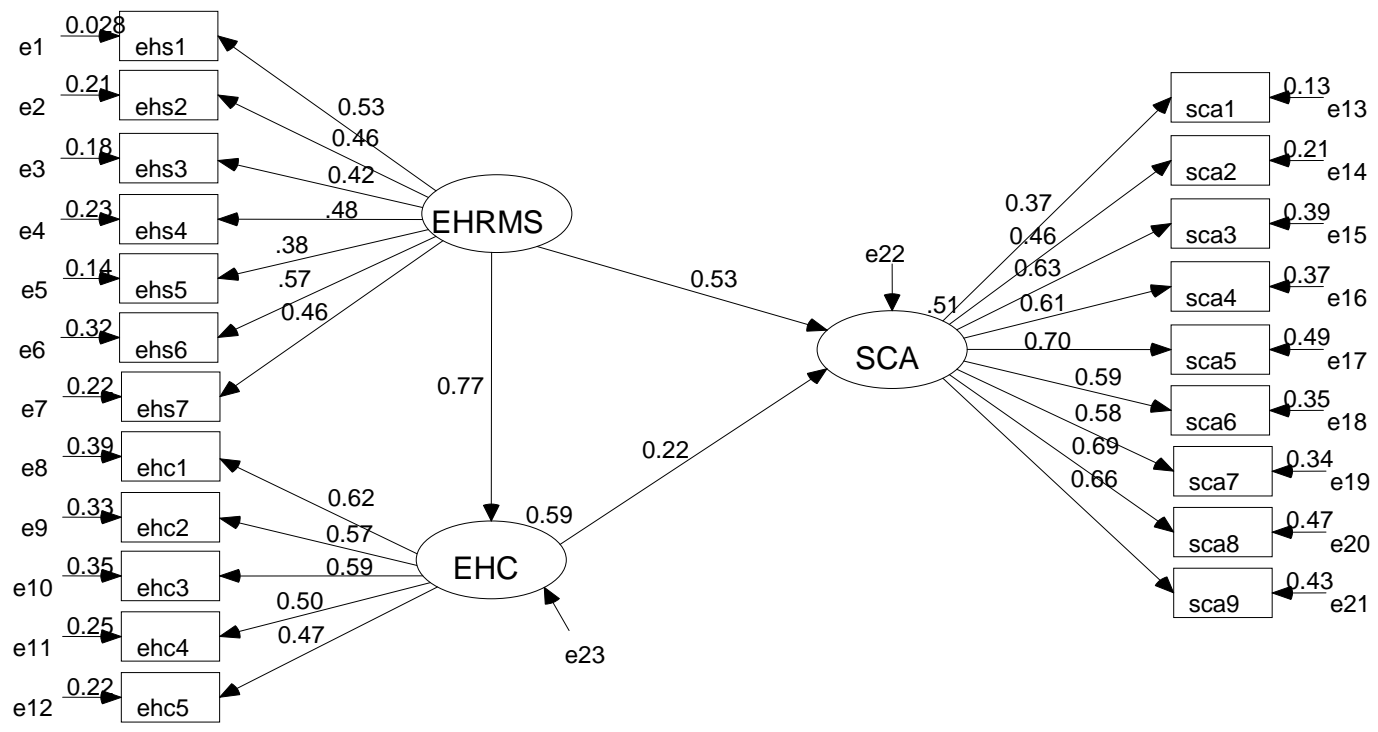

Fig. 7 The model analysis result of EHC's mediation role

\section{Research conclusion and management enlightenment}

\section{1 research conclusion}

Through the effective questionnaire survey to the general managers, department functional managers and human resource management staff, this paper takes the human capital as the mediating variable and makes an empirical test on the relationship between human resource management system and sustainable competitive advantage. The results show that: under different strategies, different types of human capital play a part of mediating role. However, from the results of calculation, the mediating effects of internal development human capital is stronger than external acquisition human capital. The mediating effect of internal development human capital accounts for $42.84 \%$ of the total effect. It shows that enterprises adopting differentiation strategy can improve the level of human capital matching with the demand of differentiation strategy through the practice of internal human resource 
management system, thus achieving the goal of improving the sustainable competitive advantage of enterprises. The mediating effect of external acquisition human capital accounts for $24.2 \%$ of the total effect. It shows that enterprises adopting cost reduction strategy the enterprise can use external human resources management system for management practices. According to the percentage of the mediating effect of the two mediating models, the mediating effect of internal development human capital is greater, the hypothesis of $\mathrm{H} 7$ is valid. This empirical result shows that, with the increasingly rapid development of economic globalization, the tangible physical capital in enterprises is no longer the main decisive capital form. The Enterprise pays attention to the staff personal knowledge, the skill and the ability cultivation through the training, the salary drive and so on way, through this way of "internal development ", it can obtain human capital with high scarcity, imitability and non-substitutability, which plays a more important role in supporting the enterprises to gain competitive advantage.

\section{2 management enlightenment}

According to the research conclusion, this paper puts forward the following two points of enterprise management enlightenment.

\subsection{1the characteristics of human capital needed by enterprises under different competitive strategies should be different}

Under the circumstances of increasingly fierce global competition, the external environment of enterprises are changing, and the strategic objectives of enterprises need to be adjusted. The differentiation strategy and the cost reduction strategy need different characteristics of human capital, the differentiation strategy is matched with the internal development human capital, and the cost reduction strategy is matched with the external acquisition human capital. The knowledge form, skill form and ability form of the two kinds of human capital are different.

The internal development human capital pays more attention to the employee's special knowledge, mental skill, knowledge skill, innovative ability and organizational learning ability. External acquisition human capital focuses on the universal knowledge of employees, action skills, executive ability, and so on. The human resource management system of an enterprise should also focus on different competitive strategies.

\subsection{2 different competitive strategies require different human resource management systems to match}

In order to matche the competitive strategy of the enterprise, it puts forward higher requirements for the practice of human resource management, different competitive strategies require different human resource management practices. In the cultivation of internal development human capital, internal human resource management system should pay more attention to "internal development" , pay more attention to the development of employees' creativity and initiative, and pay attention to the long-term cultivation of human capital needed by enterprises and work autonomy. For example, according to individual needs to provide targeted training for employees, salary incentives must to match the actual work ability of employees, and enhance communication and knowledge sharing with employees, strengthen organizational learning to enhance organizational learning ability, continuously cultivate staff loyalty to the enterprise. The internal development human resource management system cultivates the employees with the characteristics of clear self-demand orientation, high education level, high knowledge, skills and ability, and the employees also pay more attention to personal development planning and the continuous realization of personal value. Enterprises adopting cost reduction strategy should pay more attention to "external acquisition" in specific human resource management. Enterprises hire more directly from the outside rather than from the inside, and pay more attention to the skills they already have, it does not focus on investing in employees and cultivating higher levels of human capital later in life.

\section{References}

Abdul A B A, Abdul S H A, Manal A(2017). Competitive advantage based on human capital and its impact on organizational sustainability: applied study in jordanian telecommunications sector [J]. Journal of Management and Sustainability, 7(1):64-75. 
Alfes K, Shantz A D, Truss C, Soane E C(2013). The link between perceived human resource management practices, engagement and employee behaviour: a moderated mediation model[J]. The International Journal of Human Resource Management, 24(2): 330-351.

Bai P M, Dorenbosch L(2015). Age-related differences in the relations between individual ised hrm and organisational performance: a large-scale employer survey[J]. Human Resource Management Journal, 25(1):41-61.

Carmeli A(2004). Strategic human capital and the performance of public sector organizations[J]. Scandinavian Journal of Management, 20(3): 375-392.

Chin-Yen L, Tsung-Hsien K(2007). The mediate effect of learning and knowledge on organizational performance[J]. Industrial Management \& Data Systems, 107(7): 1066-1083.

Delery J E, Doty H D(1996). Modes of theorizing in strategic human resource management: tests of universalistic, contingency, and configurational performance predictions[J]. Academy of Management Journal, 39(1): 802-835.

Dyer L, Reeves T(1995). HR Strategies and firm performance: What do we know and where do we need to go[J]. International Journal of Human Resource Management, 6(3): 656-670.

Gill C(2008). Don't Know, Don't care: an exploration of evidence based knowledge and practice in human resource management [J]. Human Resource Management Review, (28): 103-115.

Greer C R, Lusch R F, Hitt M A A(2017). Service perspective for human capital resources: a critical base for strategy implementation [J].Academy of Management Perspectives, 31(2):137-158.

Hanedaa S, Itob K(2018). Organizational and human resource management and innovation: which management practices are linked to product and/or process innovation? [J]. Research Policy, 47 (3): 194-208.

Helfat C E, Peteraf M A(2003). The dynamic resource-based view: capability lifecycles[J]. Strategic Management Journal, 24(10) : 997-1010.

Huang L C, Ahlstrom D, Lee A Y P(2016). High performance work systems, employee well-being and job involvement: an empirical study[J]. Personnel Review, 45(2): 296-314.

James P. G., Patrick C. F., Wenchuan L. Sarah M(2009). High performance work systems in ireland: human resource and organizational outcomes[J]. The International Journal of Human Resource Management, 20(1): 112-125.

Jiang Jianwu, Zhao Shuming(2011). Differences human resource management practices and the impact mechanism of employee creativity[J]. Reform, (9) : 111-120.

Kianto A, Sáenz J, Aramburu N(2017). Knowledge-based human resource management practices, intellectual capital and innovation [J]. Journal of Business Research, (81) :11-20.

Li Xinjian, Li Yi, Wei Haibo(2017). Organizational human capital: a perspective of strategic management [J] . Foreign Economy and management, 39(1) : 42-55.

Li Xuefeng, Jiang Chunyan(2011). Strategic human resource management and corporate performance: the moderating role of unfair competition and government support[J]. Managing the world, (8):182-183

Lin Xinqi, Ding He(2017). The impact of human resource management intensity on employee innovation behavior -- An mediated regulatory model[J]. Soft Science, 31(12) : 60-64.

MacDuffie J P(1995). Human resource bundles on manufacturing performance: Organisational logic and flexible production systems in the world auto industry[J]. Industria1 and Labor Relations Reviews, 48(2): 197-221.

Medina C C, Cabrales A L., Cabrera R V(2011). Leveraging the innovative performance of human capital through hrm and social capital in spanish firms[J]. The International Journal of Human Resource Management, 22(4): 807-828. 
Ni Jiacheng, Li Huajing, Lin Hanchuan(2018). Human capital, knowledge transfer performance and entrepreneurial growth: A cross-case study based on internet context[J]. Research and development management, 30(1) : 47-59.

Pereira C M M, Gomes J F S(2012). The Strength of human resource practices and transformational leadership: impact on organisational performance[J]. The International Journal of Human Resource Management, 23(20): 4301-4318.

Ployhart R E(2015). Strategic organizational behavior (strobe): the missing voice in the strategic human capital conversation [J]. Academy of Management Perspectives, 29(3): 342-356.

Schuler R S, Jackson S E(1987). Linking competitive strategies with human resource management practices[J]. Academy of Management Executive, 1(3): 207-219.

Sun Rui(2014). Strategic human resource management, organizational innovation climate and $\mathrm{r} \& \mathrm{~d}$ personnel innovation[J]. Research Management, 35(8) : 34-43.

Takeuchi R, Chen G, Lepak D P(2009). Through the looking glass of a social system: cross level effects of high performance work systems on employees' attitudes[J]. Personnel Psychology, 62 (3): 1-29.

Tang Guiyao, Chen Yang, Yu Bingjie, Wei Liqun. A study on the relationship between strategic human resource management and new product development performance[J]. Scientific Research Management, 2016, 37(11) : 99-106.

Tian Lifa(2017). Best human resource management practices, organizational climate strengths and firm performance[J]. Journal of Management Engineering, 31(2) : 1-8.

Wang X L H, Yun Z, Cullinane N(2015). how does the human resource department's client relationship management impact on organizational performance in china? mediate effect of human capital [J].South African Journal of Economic and Management Sciences, 18 (3): 291-307.

Wang Xia, Wu Jiabao(2016). An empirical study on the relationship among human resource management, organizational learning, and organizational performance[J]. Management Science in China, 24(1) : 833-836

Yang Hao, Liu Jiawei(2015). A study on the relationship between best human resource management practices and firm Performance[J]. Scientific Research Management, 36(1) : 265-271.

Yeh C-C R, Chen S-J(2007). A study of human resource investment, human capital, and firm performance[D]. Guang Zhou: National Sun Yat-sen University, 2007.

Youndt M A(1998). Human resource management systems, intellectual capital, and organization performance[D]. Dissertation. Philadelphia: Pennsylvan ia State Universit.

Youndt M A, Snell S A, Dean J W Jr., Lepak D P(1996). Human resource management, manufacturing strategy, and firm performance[J]. Academy of Management Journal, 39(4): 836-866.

Youndt M A, Subramaniam M, Snell S A(2004). Intellectual capital profiles: an examination of investments and returns[J]. The Journal of Management Studies, 41(2): 335-361.

Zhao Shuming, Sun Xiuli(2016). CEO's transformational leadership behavior, strategic human resource management and firm performance - The Regulatory role of HRM capability[J]. Nankai Management Review, 9(5): 66-76.

Zhu Weimin(2009). Strategic human resource management and enterprise knowledge creation: an empirical study on technology-based enterprises[J]. Scientific Research, 27(8) : 1229-1237.

Li Xinchun, Ma Jun, he Xuan(2019). The contribution rate of institutional evolution, entrepreneurial human capital and social capital[J]. Research Management, 4012:51-61.

Li Genqiang, Meng Yong, Liu Renjing(2019). The impact of developmental human resource management practices on job performance: The role of person-organization fit and career commitment[J]. Scientific Research Management, 40(9):199-210. 